\title{
Two-process model for the atmospheric weathering, oxidation and ageing of diesel soot
}

\author{
Artur Braun $^{1}$ \\ Received 27 December 2008; revised 26 February 2009; accepted 12 March 2009; published 14 April 2009.
}

[1] The weathering characteristic of diesel exhaust particulate (DEP) matter is spectroscopically obtained by an atmospheric study under realistic, ambient conditions. DEP subjected to weathering by exposure to ambient atmosphere (air, humidity, solar radiation, and temperature variation) for seven weeks shows systematic changes in $\mathrm{C}(1 \mathrm{~s})$ x-ray absorption spectra. Quantitative analysis suggests that volatile polycyclic aromatic hydrocarbons are released from the DEP by desorption, paralleled or followed by decomposition and reaction of the amorphous part of the solid, non-volatile carbon and potential other volatile species. The observed spectral changes are rationalized in a simple two phase model and parameterized, combining desorption of volatiles and oxidation of carbon matrix. The weathering characteristics of soot is generalized toward biomass burning products and identified as a vector quantity to be implemented for climate modelling. Citation: Braun, A. (2009), Two-process model for the atmospheric weathering, oxidation and ageing of diesel soot, Geophys. Res. Lett., 36, L07810, doi:10.1029/2008GL037077.

\section{Introduction}

[2] The fate of soot with respect to weathering and atmospheric ageing is important for the assessment of its impact on climate and human health [Chameides and Bergin, 2002; Zuberi et al., 2005; Folberth et al., 2005]. Atmospheric $\mathrm{CO}_{2}$ modelling studies typically assume that $100 \%$ of the carbon flux from reactive carbon compounds (RCC) is directly released as $\mathrm{CO}_{2}$, hence not accounting for photochemistry and physical removal of the emitted RCC before a particular fraction is converted to $\mathrm{CO}_{2}$. Folberth et al. [2005] found in their transport model that $2 / 3$ of the $1823 \mathrm{TgC} / \mathrm{y}$ of reactive carbon compounds are photochemically oxidized in the atmosphere to produce $\mathrm{CO}_{2} .20 \%$ of the RCC are back-deposited as intermediate oxidation products by wet and dry processes. It has been shown [Weingartner et al., 1995, 1997; Zuberi et al., 2005] that synthetic soot surrogates and diesel exhaust become hydrophilic upon aging, particularly under strongly oxidizing conditions. The water uptake increases the soot particle size and allows for more efficient soot removal from the troposphere by rainout. In addition, aged soot acts as cloud condensation nucleus, a fact which hitherto was not included in climate models.

[3] Diesel soot (diesel exhaust particulate matter, DEP) is an important constituent in airborne particulate matter (PM)

\footnotetext{
${ }^{1}$ Laboratory for High Performance Ceramics, Swiss Federal Laboratories for Materials Testing and Research, EMPA, Dübendorf, Switzerland.

Copyright 2009 by the American Geophysical Union. 0094-8276/09/2008GL037077\$05.00
}

and can to some extent be characterized by its distinct graphite-like nature. Stacked graphene sheets, often only few nanometer small and directly visible in transmission electron micrographs [Ishiguro et al., 1997], cause broad Bragg reflexes in x-ray diffractograms that can be matched with the graphite structure [Braun et al., 2005], and a wellpronounced $\mathrm{C}=\mathrm{C}$ double resonance at $285 \mathrm{eV}$ in $\mathrm{x}$-ray absorption spectra that can be linked to the solid carbon matrix [Braun et al., 2007a]. Minute differences in the diffractograms and spectra between graphite and DEP can be quantitatively associated with aliphatic side chains and aromatic soluble matter, such as polycyclic aromatic hydrocarbons and quinone groups [Ishiguro et al., 1997; Braun et al., 2007a].

[4] It was recently suggested that the graphite-like signature of DEP would become enhanced during weathering [Braun et al., 2007a]. In this context, DEP should be considered as a material with carbon atoms bound by $\mathrm{sp}^{2}$ and $\mathrm{sp}^{3}$ bonds, which to some extent contains graphitic bound carbon, but also less ordered and disordered carbon. During ageing and weathering, the less ordered carbon would participate first in the complex carbon chemistry with $\mathrm{O}_{2}, \mathrm{H}_{2} \mathrm{O}, \mathrm{CO}_{2}, \mathrm{SO}_{2}$, and so on. While weathered aerosols consist of a mixture of organics, sulfate, nitrate and ammonium, the organic component dominated by highly oxidized secondary material [Choularton et al., 2008], it is difficult to actually account for every single species in this highly complex matter. In its simplest terms, the atoms in the least ordered carbon, also and not entirely correct referred to as amorphous, would react preferably with oxygen in the air to form $\mathrm{CO}_{2}$ and then volatize. The corresponding depletion of less ordered carbon would cause a relative enhancement of the graphite-like signature of the remaining carbon. This behaviour was actually found between two DEP samples, one of which was subject to ten days of weathering [Braun et al., 2007b].

[5] The present, more systematic weathering study is carried out in support of the previous suggestion that DEP becomes relatively more graphite-like during weathering. Interestingly, spectral changes in the very early stages of weathering which were previously not discovered are presented here for the first time. Previously published models for soot oxidation at high temperatures in exhaust aftertreatment [Kandas et al., 2005; Collura et al., 2005] are adopted and modified in order to explain the atmospheric weathering of DEP.

\section{Experiment}

[6] Diesel exhaust particulate matter (DEP) was collected from the tailpipes after passenger cars diesel engine operation studies (emission test cycles MVEG-A, ultra-low 

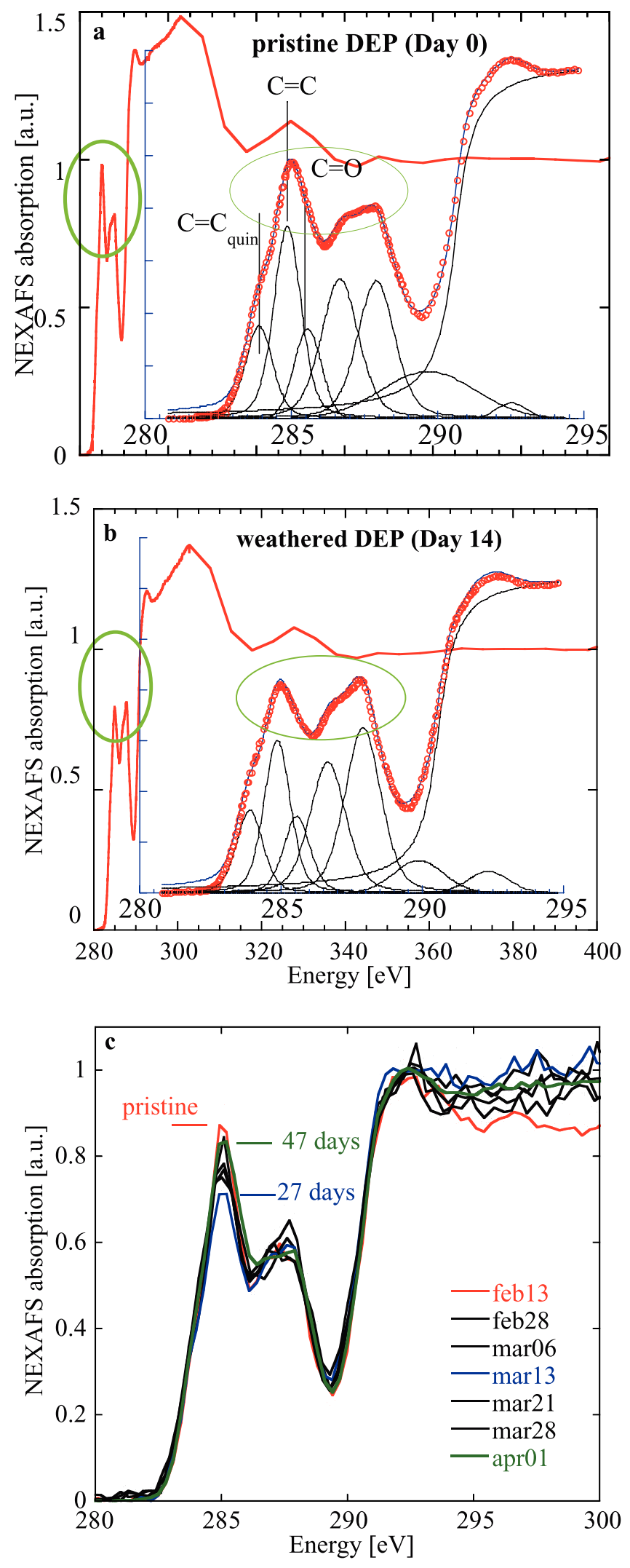

Figure 1. NEXAFS spectra of (a) pristine DEP and (b) 14 days weathered DEP with deconvolution and peak assignment. The green ellipse highlights the range of interest. (c) Comparison of all spectra from the NEXAFS runs. sulphur diesel fuel, Euro IV norm), and distributed in seven aliquots of $20 \mathrm{mg}$ each, six of which used for the weathering study and the other preserved as non-weathered reference (pristine DEP). The pristine DEP was stored in a dark room in a $2 \mathrm{~cm}^{3}$ Nalgene vial. The other soot was finely distributed in six transparent polycarbonate containers $(20 \mathrm{mg}$ of DEP per container of $50 \mathrm{~mm} \times 40 \mathrm{~mm} \times$ $20 \mathrm{~mm}$ size) which were closed, but each contained 6 holes of each $0.5 \mathrm{~cm}$ square opening per container, allowing for ventilation and circulation of air, temperature and humidity. The six containers were exposed to ambient atmosphere outside on a balcony of a $4^{\text {th }}$ floor apartment in the residential area of Brüttisellen, a village between Zürich and Winterthur beginning February 13, 2007. The first container was removed on February 28, and the weathered soot was placed in a small $2 \mathrm{~cm}^{3}$ Nalgene vial and stored in a dark room at ambient atmosphere. The other containers were removed every following week, the last one on April 1 , and stored in the same sort of vials. Thus a set of seven DEP samples with different degree of exposure to weather were obtained. The weather conditions during the campaign included dry, foggy and rainy weather, as well as sunshine, warm and frosty days and nights, and few days with snow. Detailed information (average temperature $+1{ }^{\circ} \mathrm{C}$ to $+10^{\circ} \mathrm{C}$, extreme values $-3^{\circ} \mathrm{C}$ and $+16^{\circ} \mathrm{C}$; average humidity $63 \%$ to $94 \%$, extreme values $33 \%$ and $100 \%$ ) was available from a local private weather station.

[7] Near-edge X-ray absorption fine structure spectroscopy (NEXAFS) [Braun et al., 2007b], on 250 micrometer thin pressed pellets of DEP was done at beamline 9.3.2 at the Advanced Light Source in Berkeley, California, in the second week of April 2007. The sample current was the detection signal. Every sample was subject to three scans from $260 \mathrm{eV}$ to $400 \mathrm{eV}$ with 1 second data acquisition time per step. The range from $280 \mathrm{eV}$ to $290 \mathrm{eV}$ was measured in $0.1 \mathrm{eV}$ steps.

\section{Results and Discussion}

[8] Figure 1a displays the $\mathrm{C}(1 \mathrm{~s})$ spectrum of the pristine DEP from February 13, 2007, (Day 0) prior to any weathering. The inset shows the deconvolution into Voigt functions $(70 \%$ Gaussian, FWHM $=1.1 \mathrm{eV}, 1.4 \mathrm{eV}, 1.1 \mathrm{eV}$, $1.1 \mathrm{eV}$, residuals ranged between 1.5 and 2.2 ; energy positions and FWHM fixed for all fits) and peak assignment in the relevant energy range. The dominant peak with maximum at $285 \mathrm{eV}$ is actually the convolution of three peaks, all of which bear the $\mathrm{C}=\mathrm{C}$ double bond characteristics. The central peak at $285 \mathrm{eV}$ can be caused by the graphitic bound carbon in the solid matrix, but also from soluble or volatile polycyclic aromatic hydrocarbons, which, too, can be probed by NEXAFS. The peaks at the flanks at $284 \mathrm{eV}$ and $286 \mathrm{eV}$ are due to quinone structures, with a $\mathrm{C}=\mathrm{C}$ resonance at $284 \mathrm{eV}$ and a conjugated $\mathrm{C}=\mathrm{O}$ resonance at $286 \mathrm{eV}$. Structures at 287 and $288 \mathrm{eV}$ are typically from $\mathrm{C}-\mathrm{OH}$ and $\mathrm{COOH}$, respectively [Braun et al., $2007 \mathrm{~b}]$. The $\mathrm{COOH}$ peak is prone to photo-assisted decarboxylation into $\mathrm{CO}_{2}$ or carbonate, indicated by rearrangement of spectral intensities [Braun et al., 2006].

[9] Figure $1 \mathrm{~b}$ shows the corresponding spectrum for the first weathered sample (Day 14). The most noteworthy observation is the smaller relative height of the peak at 

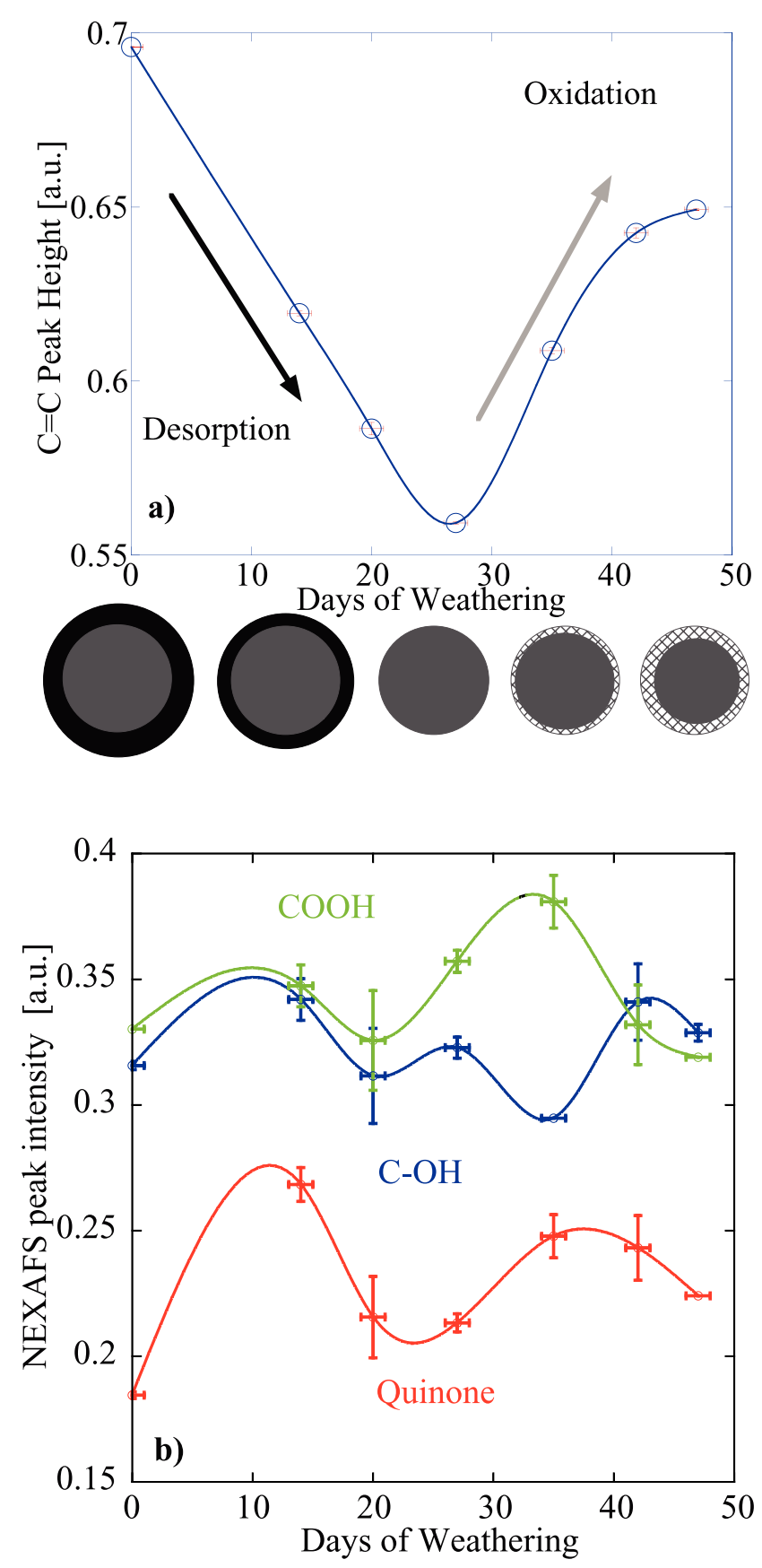

Figure 2. (a) Changes in the relative NEXAFS peak heights at $285 \mathrm{eV}$ as a function of days of weathering. Solid line is guide to the eye. Spheres at the bottom illustrate continuous loss of adsorbed volatiles upon weathering, and subsequent oxidation of the weather-exposed solid carbon core, with the amorphous part being preferentially oxidized. (b) Changes in the relative NEXAFS peak heights for quinone, $\mathrm{C}-\mathrm{OH}$ and $\mathrm{COOH}$ as a function of days of weathering. Solid lines are cubic splines to guide the eye.

$285 \mathrm{eV}$. Comparison of the calibrated and normalized spectra in Figure 1c shows that this relative height of the $\mathrm{C}=\mathrm{C}$ resonance at $285 \mathrm{eV}$ has the most significant changes upon weathering, followed by the intensities near 287 to $288 \mathrm{eV}$.
[10] To correlate soot molecular structure with weathering, the relative peak height of $\mathrm{C}=\mathrm{C}$ as determined from the deconvolution is plotted in Figure 2 across the days of weathering. The spectrum of the pristine soot has a $\mathrm{C}=\mathrm{C}$ peak height $(\mathrm{PH})$ of 0.70 . The $\mathrm{PH}$ decreases to about 0.62 after 14 days of weathering. The $\mathrm{PH}$ after three and four weeks of weathering continues to decrease to 0.59 and 0.56 , respectively, i.e. the $\mathrm{PH}$ decreases almost linearly with days of exposure of the DEP by about $20 \%$. After that, interestingly, the PH increases again to 0.61 (week \#5) and 0.64 (week \#6). The last sample, removed after 7 weeks of exposure, has a $\mathrm{PH}$ of 0.65 .

[11] The decrease of the NEXAFS peak height $(\mathrm{PH})$ at $285 \mathrm{eV}$ during the first four weeks is due to the release and loss of aromatic volatiles, which are typically trapped and adsorbed between primary particles. Repeated extraction of soluble organic matter in DEP causes similar changes in the spectra of the DEP residuals [Braun et al., 2007b]. The spectra of DEP extracts contain a distinct peak at $285 \mathrm{eV}$, but, unlike the DEP soot, no additional flank at $284 \mathrm{eV}$, which we hence assign to the solid DEP matrix. The spectrum of the DEP extract in ref. [Braun et al., 2007b, Figure 3] contains a large $\mathrm{COOH}$ peak at $288 \mathrm{eV}$; during weathering of soot, this peak becomes likely reduced by exposure to solar radiation and oxygen [Braun et al., 2006]. The subsequent increase of the PH at $285 \mathrm{eV}$ after four weeks of weathering is hence to be explained by the relative loss of material in the soot that is not organized in an aromatic molecular setting. This can be for instance the oxidation and volatilization of aliphatic carbon, with the release of $\mathrm{CO}_{2}$.

[12] The weathering of the soot can be pictured by two different processes occurring very pronounced at two stages, as illustrated in Figure 2. The model is based on the assumption that a solid graphite-like DEP particle (grey colour) is coated with soluble matter (black colour), such as residual oil, fuel, and reaction products, compare with [Collura et al., 2005]. The first stage is governed by desorption and evaporation of volatiles, and the thickness of the black illustrated coating is decreasing within the first 24 days; the second step is related to the decomposition of the remainder of the DEP by chemical reaction with air and humidity, indicated by the formation of a superficially more graphitic film that grows on top of the unreacted DEP particle by depletion of amorphous carbon, compare with [Braun et al., 2002]. In addition to that, it cannot be ruled out that intermediate carbon species are formed, which would also be detected with NEXAFS spectroscopy, including the $\mathrm{C}=\mathrm{O}$ species [Braun, 2006].

[13] But oxidation and weathering chemistry of soot is very complex and far from being understood in all details. While soot weathering has been extensively addressed in terms of carbon chemistry, relatively little work was done on sulfates, nitrates and ammonium. Their consideration would go beyond the scope of this work. Yezerets et al. [2003] conclude from their studies that extended ambient ageing forms highly reactive groups on the DEP surface, allowing for relative facile initial oxidation. Continued and repeated aging leads to continued formation of such species, which would support our finding of oscillating NEXAFS peak heights for surface functional groups (Figure 2b). 
[14] The multi-hierarchical spherular structure of DEP contains an outer shell with an inner core, which again can contain several spherical fine particles, and all structures show some graphite-like order; interestingly, this inner core could be dissolved in nitric acid [Ishiguro et al., 1997], suggesting that the DEP primary particle has some porosity providing diffusion paths towards the particle center. This implies that volatile matter may be absorbed not only on the particle surface, but also in its micropores. In contrast, Collura et al. [2005] find that solvent extraction does not alter the porosity of their samples. Either case would be in line with the desorption part of the model in Figure 2.

[15] The impact of water addition in carbon oxidation has been studied on soot, coal and other carbon forms by Petit [1991]. Oxidized coal, and probably any oxidized carbonaceous material, exhibits a highly intense chemical reaction with water vapour and also with carbon dioxide. Petit considers $\mathrm{H}_{2} \mathrm{O}$ and $\mathrm{CO}_{2}$ as probe molecules and an indicator for trace oxidation at ambient temperatures. This is in line with the hypothesized formation of meta-stable oxides attached to the carbon, and the reported anomalously high reaction rates during initial carbon oxidation [Stanmore et al., 2001, section 5.1.1].

[16] Solid carbon surfaces are typically coated with functional groups, particularly quinones, carbohydroxide and carboxyl groups, including the aforementioned sulfates, for example, which are beyond the scope of this work. Since soot has a high surface area, these groups can easily be detected. Figure $2 b$ shows the transient of the relative peak heights at $284 \mathrm{eV}$ and $286 \mathrm{eV}$, indicative to benzo-quinone, $287 \mathrm{eV}$ indicative to $\mathrm{C}-\mathrm{OH}$, and $288 \mathrm{eV}$ indicative to $\mathrm{COOH}$. The solid cubic splines guide the eye. The data suggest some trend of initial increase of these surface functional groups. The oscillatory behaviour could be explained by the observations of repeatedly recurring formation of highly reactive surface groups on soot during ambient ageing [Collura et al., 2005]. However, these groups are uncovered as volatilisation of the volatile mater adsorbed on the DEP, rather than initially created as a result of atmospheric chemical reactions. Comparison with the extract spectrum in the middle [Braun et al., 2007b, Figure 3] shows that volatile or soluble aromatic species can obscure the peaks at $285 \mathrm{eV}$, whereas water soluble carboxyl has a pronounced signature in the extract spectrum. The subsequent evolution of the quinone and $\mathrm{C}-\mathrm{OH}$ structure after 14 days of weathering can be considered relatively constant, suggesting that these surface functional groups maintain their presence on the DEP surface during weathering. The variation of $\mathrm{COOH}$ is stronger, possibly because $\mathrm{COOH}$ is more prone to atmospheric photochemistry [Braun et al., 2006] than $\mathrm{C}-\mathrm{OH}$ and quinone.

[17] The weathering characteristic of DEP shows two distinct processes over the course of about 50 days of weathering, this is, an initial desorption and a subsequent oxidation process. If the soot particulates had been fluidized in the actual atmosphere, the weathering would have been more intense. While the lifetime of soot in the atmosphere is difficult to assess and may probably be around one week [Chung and Seinfeld, 2002], some models predict a lifetime of several weeks [Gaffney et al., 2004] or even 100 days [Croft et al., 2005]. Overall, the weathering of our specimen would have been accelerated, and the effects would have been observed on a shorter time scale when the soot in this experiment had been fluidized directly to the open atmosphere. Possibly, secondary formed matter such as sulfates have condensed less on the soot in our experiment than it would have been on fluidized DEP. The pattern, i.e., the two process characteristics as such would probably not change. Inclusion of such weathering characteristics in atmospheric and climate modelling algorithms would likely yield a more accurate description of atmospheric and climate scenarios. The present study was carried out with DEP, because diesel soot is a relatively well studied and known material, more so than wood smoke and other soot from biomass burning, and comes in standard reference materials [Braun et al., 2007a]. The major part of soot in the atmosphere and troposphere comes from wildfires; DEP represents only a lesser part to the overall soot. Soot from wildfires and other biomass burning processes have likely different weathering characteristics, because their soot structure is quite different [Braun et al., 2007b]. However, similar surface functional groups as well as a thin oxygenated interface layer were recently detected with NEXAFS spectroscopy on biomass particles [Tivanski et al., 2007]. In the extreme case, no solid core might be present, and the weathering characteristics would contain only the desorption step. This may hold for some biomass soot, for instance. In the extreme case of dry DEP soot, no or negligible amount of volatiles would be absorbed. Hence, the solid core oxidation step would dominate the weathering characteristics. The approach presented here is specific to the element carbon; species under scrutiny like sulfates, nitrates and ammonium were not considered, but can generally be accounted for by NEXAFS spectroscopy. A very early fundamental electron spectroscopy work pointed to the importance of sulfate formation on soot [Novakov et al., 1974]. Future weathering studies with subsequent characterization of the molecular structure of the soot and its intermediate structures will provide an improved basis for accurate atmospheric and climate modelling work.

[18] Acknowledgments. The ALS is supported by the Office of Basic Energy Sciences, U.S. Department of Energy, contract DE-AC02$05 \mathrm{CH} 11231$. The author had funds from the European Union, contract MIRG 2006-042095.

\section{References}

Braun, A. (2006), Some comments on "Soot surface area evolution during air oxidation as evaluated by small angle X-ray scattering and $\mathrm{CO}_{2}$ adsorption", Carbon, 44, 1298-1352.

Braun, A., M. Bärgtsch, A. Schnyder, R. Kötz, O. Haas, and A. Wokaun (2002), Evolution of BET internal surface area in glassy carbon powder during thermal oxidation, Carbon, 40, 375-382.

Braun, A., et al. (2005), X-ray scattering and spectroscopy studies on diesel soot from oxygenated fuel under various engine load conditions, Carbon, $43,2588-2599$

Braun, A., S. Wirick, A. Kubatova, B. S. Mun, and F. E. Huggins (2006), Photochemically induced decarboxylation in diesel soot extract and sodium alginate, Atmos. Environ., 40, 5837-5844.

Braun, A., N. Shah, F. E. Huggins, and G. P. Huffman (2007a), Carbon speciation of diesel exhaust and urban particulate matter NIST standard reference materials with C(1s) NEXAFS spectroscopy, Environ. Sci. Technol., 41, 173-178.

Braun, A., F. E. Huggins, A. Kubatova, S. Wirick, M. M. Maricq, B. S. Mun, J. D. McDonald, K. E. Kelly, N. Shah, and G. P. Huffman (2007b), Toward distinguishing woodsmoke and diesel exhaust in ambient particulate matter, Environ. Sci. Technol., 42, 374-380.

Chameides, W. L., and M. Bergin (2002), Climate change: Soot takes center stage, Science, 297, 2214-2215. 
Choularton, T. W., et al. (2008), The influence of small aerosol particles on the properties of water and ice clouds, Faraday Discuss., 137, 205-222.

Chung, S. H., and J. H. Seinfeld (2002), Global distribution and climate forcing of carbonaceous aerosols, J. Geophys. Res., 107(D19), 4407, doi:10.1029/2001JD001397.

Collura, S., N. Chaoui, B. Azambre, G. Finqueneisel, O. Heintz, A. Krzton, A. Koch, and J. V. Weber (2005), Influence of the soluble organic fraction on the thermal behaviour, texture and surface chemistry of diesel exhaust soot, Carbon, 43, 605-613.

Croft, B., U. Lohmann, and K. von Salzen (2005), Black carbon ageing in the Canadian Centre for Climate modelling and analysis atmospheric general circulation model, Atmos. Chem. Phys., 5, 1931-1949.

Folberth, G., D. A. Hauglustaine, P. Ciais, and J. Lathière (2005), On the role of atmospheric chemistry in the global $\mathrm{CO}_{2}$ budget, Geophys. Res. Lett., 32, L08801, doi:10.1029/2004GL021812.

Gaffney, J. S., N. A. Marley, M. M. Mary, and M. Cunningham (2004), Natural radionuclides in fine aerosols in the Pittsburgh area, Atmos. Environ., 38, 3191-3200.

Ishiguro, T., Y. Takatori, and K. Akihama (1997), Microstructure of diesel soot particles probed by electron microscopy: First observation of inner core and outer shell, Combust. Flame, 108, 231-234.

Kandas, A. W., I. G. Senel, Y. Levendis, and A. F. Sarofim (2005), Soot surface area evolution during air oxidation as evaluated by small angle $\mathrm{x}$ ray scattering and $\mathrm{CO}_{2}$ adsorption, Carbon, 43, 241-251.

Novakov, T., S. G. Chang, and A. B. Harker (1974), Sulfates as pollution particulates: Catalytic formation on carbon (soot) particles, Science, 186, $259-261$.
Petit, J. C. (1991), A comprehensive study of the water vapour/coal system: Application to the role of water in the weathering of coal, Fuel, 70, $1053-1058$

Stanmore, B. R., J. F. Brilhac, and P. Gilot (2001), The oxidation of soot: A review of experiments, mechanisms and model, Carbon, 39, 2247-2268.

Tivanski, A. V., R. J. Hopkins, T. Tyliszczak, and M. K. Gilles (2007), Oxygenated interface on biomass burn tar balls determined by single particle scanning transmission x-ray microscopy, J. Phys. Chem. A, $111,5448-5458$.

Weingartner, E., U. Baltensperger, and H. Burtscher (1995), Growth and structural change of combustion aerosols at high relative humidity, Environ. Sci. Technol., 29, 2982-2986.

Weingartner, E., H. Burtscher, and U. Baltensperger (1997), Hygroscopic properties of carbon and diesel soot particles, Atmos. Environ., 31, 2311 2327.

Yezerets, A., N. W. Currier, H. A. Eadler, A. Suresh, P. F. Madden, and M. A. Branigin (2003), Investigation of the oxidation behaviour of diesel particulate matter, Catalysis Today, 88, 17-25.

Zuberi, B., K. S. Johnson, G. K. Aleks, L. T. Molina, M. J. Molina, and A. Laskin (2005), Hydrophilic properties of aged soot, Geophys. Res. Lett., 32, L01807, doi:10.1029/2004GL021496.

A. Braun, Laboratory for High Performance Ceramics, Swiss Federal Laboratories for Materials Testing and Research, EMPA, Überlandstrasse 129, CH-8600 Dübendorf, Switzerland. (artur.braun@alumni.ethz.ch) 